\title{
Water quality assessment of River Ganga and Chilika lagoon using AVIRIS-NG hyperspectral data
}

\author{
S. Chander ${ }^{1, *}$, Ashwin Gujrati ${ }^{1}$, K. Abdul Hakeem ${ }^{2}$, Vaibhav Garg ${ }^{3}$, \\ Annie Maria Issac ${ }^{2}$, Pankaj R. Dhote ${ }^{3}$, Vinay Kumar ${ }^{3}$ and Arvind Sahay ${ }^{1}$ \\ ${ }^{1}$ Space Applications Centre, Indian Space Research Organisation (ISRO), Ahmedabad 380 015, India \\ ${ }^{2}$ National Remote Sensing Centre, ISRO, Hyderabad 500 037, India \\ ${ }^{3}$ Indian Institute of Remote Sensing, ISRO, Dehradun 248 001, India
}

Remote sensing is a vital tool to assess water quality parameters in water bodies like rivers, lakes, estuaries and lagoons. All these fall under the category of optically complex waters (case 2), where water-leaving radiance is affected by optically active water constituents and bottom substrate. The present study estimates water quality parameters, viz. turbidity, suspended sediment concentration and chlorophyll in River Ganga in Buxar (Bihar), and Howrah (West Bengal) and Chilika lagoon (Odisha) using hyperspectral reflectance data of AVIRIS-NG. Concurrent ground-truth data of water samples were collected and simultaneous spectro-radiometer measurements were made in synchronous with the AVIRIS-NG flight over the study area. Semi-analytical simulation modelling followed by inversion and contextual image analysis-based methods were used for estimating the water quality parameters. Water turbidity maps were generated for both the study sites. Over Ganga river, water was relatively clear in Buxar (6.87-20 NTU, TSS 42-154 mg/l), while it was extremely turbid in Howrah (50-175 NTU, TSS 75-450 mg/l). In Chilika lagoon, water was more turbid in the northern sector, which may be due to the river input and resuspension from shallow bathymetry. The results suggest that the small-scale changes in turbidity due to point sources like river tributaries or sewerage discharges can be identified using hyperspectral data. The imaging spectroscopy data over water are a key source to find out potential locations of water contamination.

Keywords: Hyperspectral data, remote sensing reflectance, semi-analytical algorithms, spectroradiometer.

\section{Introduction}

MONITORING the water quality parameters is an important indicator to measure the productivity and eutrophication of the river-water system. The concentration of optically active constituents can provide remarkable insight into

*For correspondence. (e-mail: schander@sac.isro.gov.in) physical, biological and biogeochemical processes within the inland water systems. The change in light attenuation by water column may deteriorate aquatic life and primary productivity, as well as the growth of aquatic vegetation ${ }^{1}$. With the increasing water pollution, degradation of water quality had caused widespread concern in the society. Water quality of inland water bodies degrades due to lack of dissolved oxygen and high nutrient concentrations. Industrial wastes, urbanization of catchment areas, domestic sewage, and fertilizer run-off from agricultural lands are possible causes for the degradation of water quality of river systems. The largest source of water pollution in India is untreated sewage ${ }^{2}$.

The optical properties of case-1 water co-vary with chlorophyll concentration, whereas case-2 waters are optically complex, where all constituents vary independently. Hence, a bio-optical model for case- 2 waters should include other parameters. For example, there can be terrestrial input from the surrounding land, so apart from chlorophyll, colour dissolved organic matter (CDOM) and suspended sediments should also be included in the forward simulations of remote sensing reflectance $\left(r_{\mathrm{rs}}\right)$. These water constituents have different spectral scattering and absorption characteristics, and can change the total $r_{\mathrm{rs}}$ drastically. Further, it is a challenge to model river waters, as they are a combination of optically complex water and optically shallow water. In optically shallow waters, the water-leaving radiance also includes the bottom reflected light. Bottom type also has equal significance, i.e. different bottom types, like constant, sand, sediments and grass can change the spectral shape of the total remote sensing reflectance. A number of retrieval algorithms exist for estimation of water quality constituents from spaceborne missions. However, most of these algorithms have been applied mainly on the case-1 waters. Operational monitoring in case- 2 waters has been limited because of the inherent complexities of the system, and the coarse spectral and spatial resolution of available satellite systems. Inland waters have complexity ranging from land run-off to bottom reflection. Understanding of water quality of inland waters is important as 
they play a major role in the quality of life; however, they are under continuous stress due to human activities and natural events ${ }^{3}$. Water colour associated with inland systems is typically characterized by high levels of total suspended sediments (TSS), CDOM and chlorophyll, exhibiting a complex mixture of contributing colour constituents.

Traditional water monitoring based on in situ sampling and laboratory measurements is difficult to reflect its distribution in time and space. Remote sensing provides a better understanding in the spatial variation of water quality for its wide monitoring range, short cycle and comparable accuracy. Several studies have confirmed that remote sensing can meet the demand for water quality studies. The AVIRIS data should be ideal for case-2 water retrieval due to the many spectral channels available, and the wide spectral range from 400 to $2500 \mathrm{~nm}$. The longer wavelength channels can be used for effectively measuring the atmospheric correction in turbid waters. Using the instrument's capability of measuring reflectance for a large number of bands, it also provides a good opportunity for simultaneous retrieval of multiple components. The high spatial resolution of AVIRIS data will be advantageous for river water quality estimation, because generally river water has point source pollution.

The objectives of the present study are: (1) to develop an algorithm for deriving the concentration of water quality parameters for the inland water bodies from remote sensing imagery, and assess the agreement with in situ data, (2) to select the suitable semi-analytical algorithm based solution of radiative transfer equation using site specific field measurements for different aquatic optical properties and bottom types and (3) to develop a spectral library of reflectance in the inland water bodies that includes GPS locations and in situ reflectance spectra for various concentrations of turbidity.

\section{Study area}

River Ganga originates from the Garhwal of the Himalaya $\left(30^{\circ} 55^{\prime} \mathrm{N}, 79^{\circ} 7^{\prime} \mathrm{E}\right)$ as the Bhagirathi. The river makes its path through the Himalaya and flows a distance of about $2525 \mathrm{~km}$. The Ganga River basin accounts for a little more than one-fourth $(26.3 \%)$ of India's total geographical area, and is the biggest river basin in country. Since River Ganga is the main source of drinking water supply for the surrounding areas, its pollution leads to major health risks. Three main causes of pollution that degrades the quality of water in this river system are agriculture, industrial water discharge and domestic sewage that is directly discharged into the river ${ }^{4}$.

Chilika lagoon in Odisha is the largest coastal lagoon in India and the second largest lagoon in the world with width of $20 \mathrm{~km}$ and length of $64 \mathrm{~km}$. In 1981, Chilika was designated as the first Indian wetland of international importance under the Ramsar Convention. It is a brackish water lagoon, spread over the east coast of India, covering an area of over $1100 \mathrm{sq} . \mathrm{km}$. The lagoon is separated from the Bay of Bengal by sand bar of $60 \mathrm{~km}$ length. The water quality of the lagoon changes widely over different seasons and exhibits different ecological characteristics in localized pockets. The physico-chemical studies by the Chilika Development Authority (CDA) indicate highly turbid waters due to strong mixing of overlying water with sediments, the transparency values ranging between $8 \mathrm{~cm}$ and $117 \mathrm{~cm}$. It has been reported that the total sediment load discharged into the lagoon has increased from $1.8 \mathrm{M}$ ha in 1998 to $2.94 \mathrm{M}$ ha in 2001 (ref. 5).

Considering the importance of the study area, it was proposed to carry out the study to analyse water quality using hyperspectral data by acquiring AVIRIS-NG data over a few reaches of the main stream of River Ganga and Chilika lagoon (Figure 1). AVIRIS-NG hyperspectral data were collected over the study region from an aircraft flying at approx. $4-8 \mathrm{~km}$ altitude. AVIRIS-NG data contain 425 bands from 370 to $2510 \mathrm{~nm}$ with FWHM of 5.5$6 \mathrm{~nm}, 4-8 \mathrm{~m}$ spatial resolution and 32-bit radiometric resolution radiance data in $\mu \mathrm{W} / \mathrm{cm}^{2} / \mathrm{nm} / \mathrm{sr}$. As part of the concurrent ground truth collection, water samples (for laboratory analysis) were collected within $\pm 2 \mathrm{~h}$ of the time of flight and simultaneous spectroradiometer, sun-photometer, echo sounder measurements were taken at Buxar (18 locations) and Howrah (42 stations), along the Ganga on 23 February and 25-28 February 2016 respectively. AVIRIS flight over Howrah was originally scheduled on 25 February 2016, but because of weather conditions, the imaging was carried out on 3 March 2016. Over Chilika lagoon, a dedicated field campaign was conducted during 24-28 December 2015 and 48 stations were covered in synchronous with AVIRIS-NG flight (26-28 December 2015). A field-based spectral library was developed with respect to various concentrations of turbidity. Atmospherically corrected NASA product was used for analysis. Table 1 presents the other flight parameters.

\section{Methodology}

There are various methods to estimate water quality parameters from airborne/satellite remote sensing. The first approach uses empirical models that develop statistical relations between measured field data and image reflectance ${ }^{6}$. The second approach uses physical modelling of light through the atmosphere, water column, surface and bottom to retrieve water backscatter and absorption coefficient, bottom depth and bottom reflectance $^{3}$. The third approach compares the spectral matching or spectral similarity analysis for obtaining the compositional information of the surface by comparing statistically the known spectra (field or library) and unknown image 


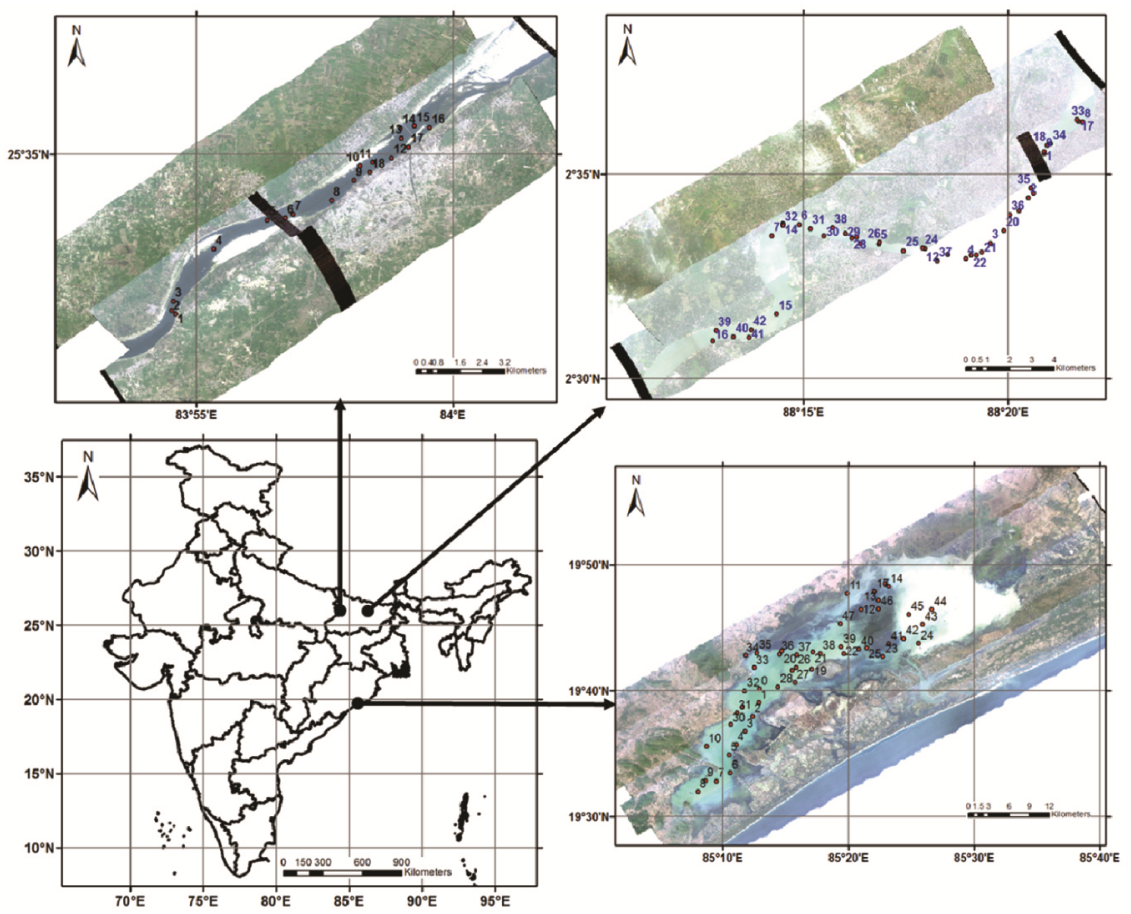

Figure 1. Location map along with AVIRIS data acquisition and in situ station locations in chronological order: Ganga River (Buxar), Ganga River (Howrah) and Chilika lagoon (Odisha).

Table 1. Details of AVIRIS-NG dataset used in the present study

\begin{tabular}{llccc}
\hline Study area & \multicolumn{1}{c}{ AVIRIS strip id (date) } & $\begin{array}{c}\text { AVIRIS strip id } \\
\text { start time (IST) }\end{array}$ & $\begin{array}{c}\text { Flight } \\
\text { altitude (m) }\end{array}$ & $\begin{array}{c}\text { Spatial } \\
\text { resolution (m) }\end{array}$ \\
\hline Ganga River, Buxar & 150 (23 February 2016) & $11: 39,11: 47,11: 56$ & 5000 & 5 \\
Ganga River, Howrah & $153(3$ March 2016) & $10: 40,10: 50$ & 5000 & 5 \\
Chilika lagoon, Odisha & $54,100,92$ (26-28 December 2015) & - & 8000 & 8 \\
\hline
\end{tabular}

spectra $^{7}$. We have examined spectral similarity analysis and semi-analytical inversion algorithms to map the optical properties of water column. Instead of using few specific bands, both our algorithms utilized the full spectral shape of the reflectance that reduces the chances of wrong interpretation.

\section{Spectral similarity analysis}

The commonly used spectral matching algorithms are spectral correlation measure ${ }^{8}$, spectral angle mapper $(\mathrm{SAM})^{9}$, Euclidean distance measure and spectral information divergence ${ }^{10}$. In the present study, the most widely used SAM spectral matching algorithm has been chosen for mapping turbidity. It is a method of comparing image spectra with individual spectra of a spectral library. The algorithm determines the similarity between two spectra by calculating the 'spectral angle $(\theta)$ ' between them, treating them as vectors in a space with dimensionality equal to the number of bands ${ }^{9}$.

$$
\cos \theta=\frac{\sum_{i=1}^{n} e_{i} r_{i}}{\sqrt{\sum_{i=1}^{n} e_{i}^{2}} \sqrt{\sum_{i=1}^{n} r_{i}^{2}}},
$$

where $e$ is the given image spectra, $r$ the reference spectra and $n$ is the number of classes. This method is insensitive to illumination since the SAM algorithm uses only the vector direction and not the vector length.

Here, entire spectral library of field-collected spectra was matched with AVIRIS-NG image spectrum at each pixel and their spectral angle $\theta$ has been measured. Wherever the least angle between two spectra was measured, the turbidity class of the field spectrum was assigned to that particular pixel. It is to be noted that SAM is not an identifier, it is only a similarity measure which indicates how similar are the specific spectral features (absorption features) in field and image reflectance spec$\operatorname{tra}^{11,12}$. For similarity analysis, it requires continuum to be removed from both the reflectance spectra prior to analysis. The continuum was removed by a mathematical 

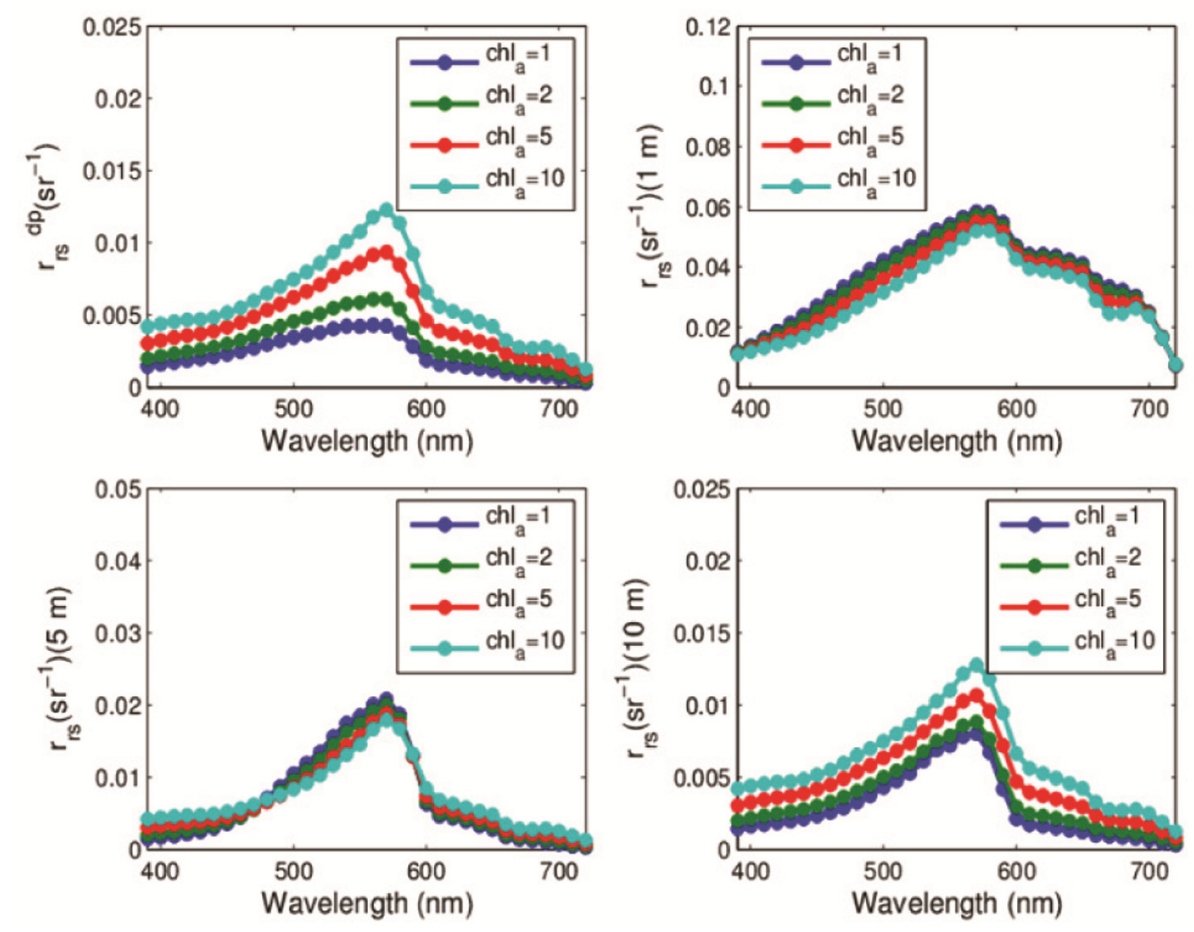

Figure 2. Simulated remote sensing reflectance $\left(r_{\mathrm{rs}}\right)$ for varying water optical properties and various depths (optically deep water, 1, 5 and $10 \mathrm{~m}$ ).

function to isolate a particular absorption feature for the analysis $^{11}$. After continuum removal, the spectra were normalized to a common reference (base line) and compared for individual absorption features, as suggested by Kokaly ${ }^{13}$.

\section{Simulation and inversion of remote sensing reflectance}

Semi-analytical models for shallow waters that have been developed by several researchers show that water column properties could be analytically derived from hyperspectral data using an optimization technique ${ }^{14-16}$. It is essential to understand the relationship between reflectance, absorption and backscattering of water for developing the analytical algorithms. We have used the semi-analytical inversion algorithms of Lee et $a l^{3}$, to retrieve the inherent optical properties (IOPs) from the AVIRISmeasured remote sensing reflectance. For shallow inland water, with the assumption of vertical homogeneity, the remote sensing reflectance $\left(\mathrm{sr}^{-1}\right)$ can be written as

$$
R_{\mathrm{rs}}=f\left(a(\lambda), b_{\mathrm{b}}(\lambda), \rho, H, T\right)
$$

where $\alpha$ is the absorption coefficient $\left(\mathrm{m}^{-1}\right), b_{\mathrm{b}}$ the backscattering coefficient $\left(\mathrm{m}^{-1}\right), \rho$ the bottom albedo, $H$ the bottom depth and $T$ is a factor that depends on the geometry of the incoming/outgoing radiance, i.e. subsurface solar zenith angle $\left(\theta_{\mathrm{w}}\right)$ and subsurface viewing angle $\left(\theta_{\mathrm{v}}\right)$.
This model divides the total $R_{\mathrm{rs}}$ into two contributions, one due to optically deep waters and the other contribution a finite bottom depth. Most of the models assume that diffuse attenuation coefficient is the same for both upward and downward directions. The uniqueness of this model lies in the fact that a different optical path elongation factor is assigned for a photon from the water column and one from the bottom. This above water $R_{\mathrm{rs}}$ can be converted into subsurface remote sensing reflectance $\left(r_{\mathrm{rs}}\right)$ using water-to-air divergence factor and a factor that accounts for the internal reflection of the water-air interface ${ }^{3,14}$.

$$
\begin{aligned}
r_{\mathrm{rs}}= & r_{\mathrm{rs}}^{\mathrm{dp}}\left[1-\exp \left(-\left(\frac{1}{\cos \theta_{\mathrm{w}}}+\frac{1.03(1+2.4 u)^{0.5}}{\cos \theta_{v}}\right) \gamma H\right)\right] \\
& +\frac{1}{\pi} \rho \exp \left(-\left(+\frac{1.04(1+5.4 u)^{0.5}}{\cos \theta_{v}}\right) \gamma H\right),
\end{aligned}
$$

where $u, \gamma$ and $r_{\mathrm{rs}}^{\mathrm{dp}}$ (deep-water remote sensing reflectance) are defined as

$$
\begin{aligned}
& u=\frac{b_{\mathrm{b}}}{a+b_{\mathrm{b}}}, \\
& \gamma=a+b_{\mathrm{b}}, \\
& r_{\mathrm{rs}}^{\mathrm{dp}}=(0.084+1.171 u) u .
\end{aligned}
$$




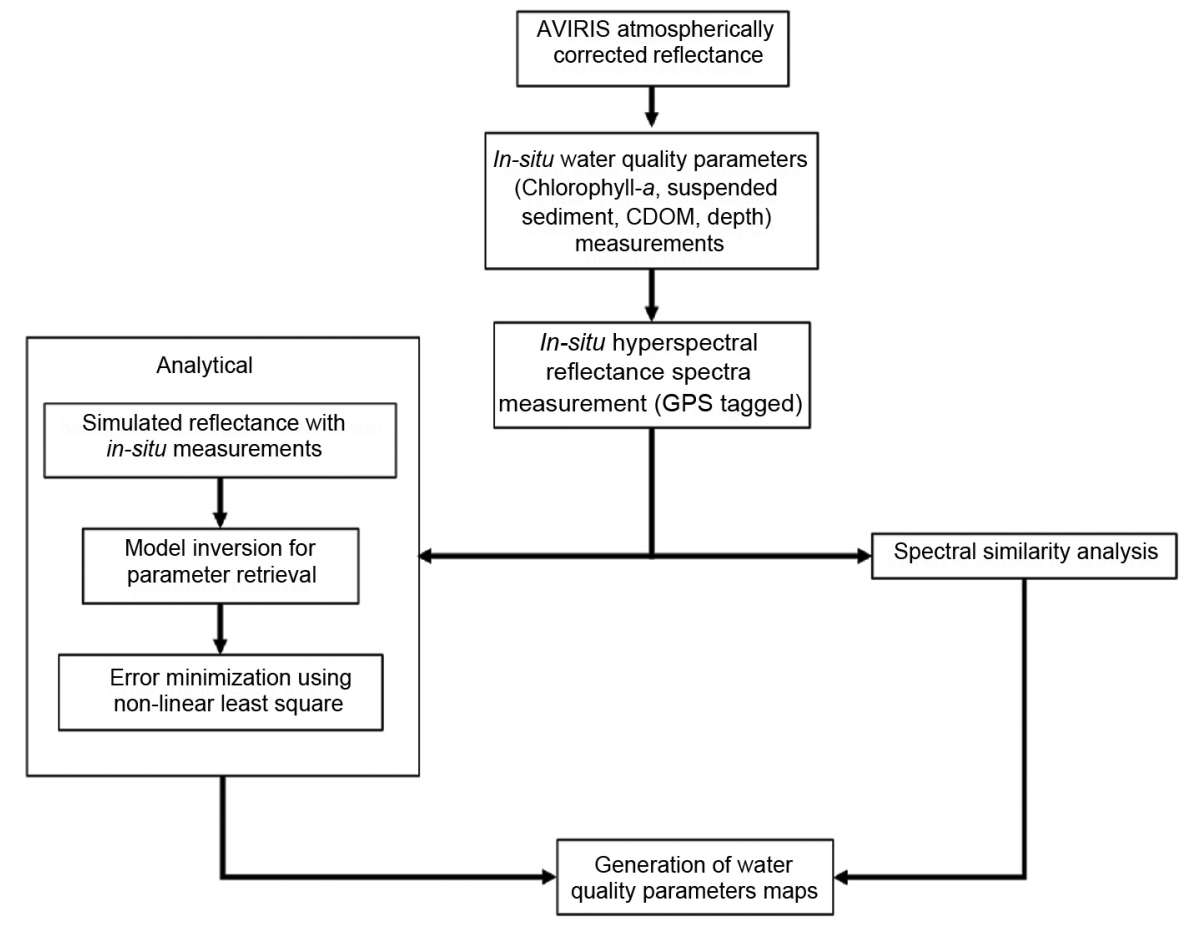

Figure 3. Flow chart of the methodology.
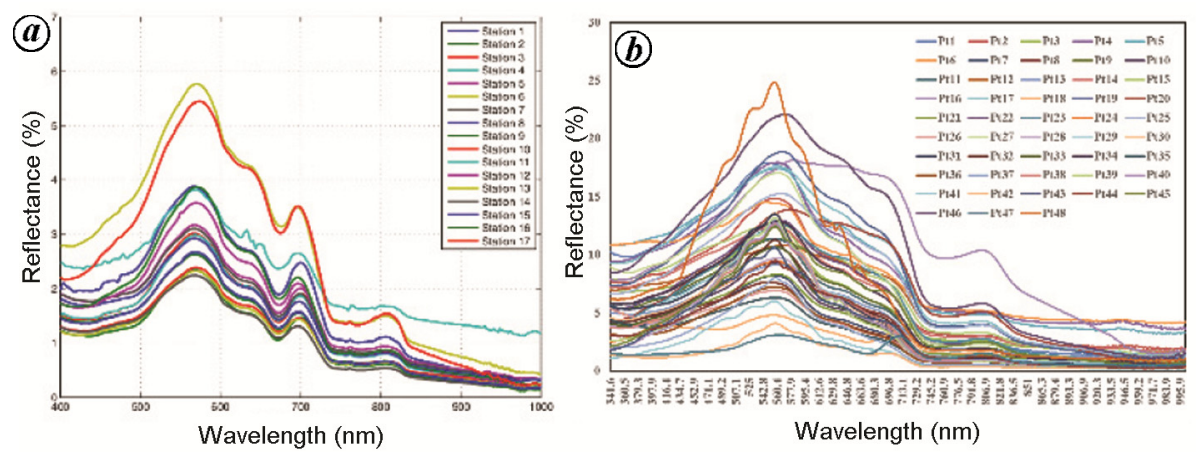

Figure 4. Spectral reflectance measured using a spectro-radiometer over (a) Ganga River (Buxar) and (b) Chilika lagoon.

Total absorption of water constituents was considered as the sum of the component absorption coefficients, i.e. natural water, phytoplankton $\left(a_{\phi}\right)$ and gelbstoff/CDOM. Absorption due to pure water was assumed as constant ${ }^{17}$. The spectral shapes of CDOM absorption were modelled using exponential law ${ }^{18}$. Region-specific absorption coefficient should be taken for best results, but due to non-availability, specific absorption coefficient as given by Lee $e t a l{ }^{3}$ was used. Backscattering due to pure water was taken from Morel and Prieur ${ }^{19}$. The backscattering due to particles was estimated using power law

$$
b_{\mathrm{bp}}(\lambda)=b_{\mathrm{bp}}(400)\left(\frac{400}{\lambda}\right)^{Y} \text {, }
$$

where $Y$ is the spectral shape parameter of particle backscattering. Forward simulations were carried out by changing the chlorophyll from 0 to $100 \mathrm{mg} / \mathrm{m}^{3}$, and backscattering coefficient CDOM from 0 to $2 \mathrm{~m}^{-1}$ to simulate $r_{\mathrm{rs}}$ for all possible combinations of water quality parameter and for various depths (optically deep, 1, 5 and $10 \mathrm{~m}$ ). Figure 2 shows one such example where $r_{\text {rs }}$ was simulated for four varying chlorophyll concentrations (1, 2, 5 and $\left.10 \mathrm{mg} / \mathrm{m}^{3}\right)$. In this case, all other water optical constituents were assumed to co-vary with the chlorophyll concentration.

For inverting the above semi-analytical model, a nonlinear least square error minimization scheme was implemented that starts with the initial guess values. This method uses Levenberg-Marquardt optimization routine for finding the best possible match. The lower and upper bounds of the unknowns, i.e. absorption due to phytoplankton, absorption due to CDOM and backscattering due to particles were kept in the range $0-2 \mathrm{~m}^{-1}$ 
Table 2. Details of in situ measured dates, turbidity and total suspended sediments concentration over the study area

\begin{tabular}{lccc}
\hline Study area & In situ measurement stations with date & Turbidity (NTU) & TSS (mg/l) \\
\hline Ganga River, Buxar & $18(23$ February 2016) & $6.87-20$ & $42-154$ \\
Ganga River, Howrah & $42(25-28$ February 2016) & $50-175$ & $75-450$ \\
Chilika lagoon & $48(24-28$ December 2015) & $1.07-70.7$ & - \\
\hline
\end{tabular}

Table 3. Statistical comparison between modelled and AVIRIS-measured remote sensing reflectance for varying site-specific conditions

\begin{tabular}{lcccc}
\hline Bottom type & CDOM slope & $Y$ parameter & $R^{2}$ & RMSE \\
\hline Sand & 0.020 & 1 & 0.9965 & $7.42 \mathrm{e}-04$ \\
Heavy vegetation & 0.020 & 1 & 0.9626 & 0.025 \\
Small vegetation & 0.020 & 1 & 0.9382 & 0.033 \\
Sand & 0.011 & 1 & 0.9885 & 0.013 \\
Sand & 0.018 & 1 & 0.9957 & $8.22 \mathrm{e}-04$ \\
Sand & 0.020 & 1 & 0.9965 & $7.42 \mathrm{e}-04$ \\
Sand & 0.020 & 0.1 & 0.9953 & $8.50 \mathrm{e}-04$ \\
Sand & 0.020 & 1 & 0.9965 & $7.42 \mathrm{e}-04$ \\
Sand & 0.020 & 2 & 0.9964 & $8.96 \mathrm{e}-04$ \\
\hline
\end{tabular}

based on their range in the natural waters. Maximum iteration along with the tolerance limit was quantified to avoid the endless looping. It is an error minimization technique that keeps on predicting the new value, unless the result converges within the given uncertainty. Figure 3 shows the complete flow chart of the methodology.

\section{Results and discussion}

Figure 4 shows the spectral response over electromagnetic spectrum collected through in situ radiometer over the study area. This differential spectral response at different locations in the river is due to variation in biophysical and biochemical properties. Over Buxar region, the reflectance spectra show a clear reflectance peak around $570 \mathrm{~nm}$, which then decreases gradually. Another peak appears around $706 \mathrm{~nm}$. The curves show less diversity when the wavelength is larger than $730 \mathrm{~nm}$. The reflectance peak near $570 \mathrm{~nm}$ may be caused by low absorption of algal pigments and/or the scattering of inorganic suspended materials and phytoplankton cells. The absorption valley from 670 to $686 \mathrm{~nm}$ may be caused by the maximum absorption of chlorophyll- $a(\mathrm{Chl}-a)$ in the red band The other reflectance peak near $706 \mathrm{~nm}$ may be due to fluorescence of Chl- $a$. Over Chilika lagoon, variety of spectra was observed, ranging from clear productive water to extreme turbid water. In the northern sector, the spectra were of typical turbid water with peak at $570 \mathrm{~nm}$, while in the southern and central sectors, the reflectance peak was observed at $555 \mathrm{~nm}$. At some of the locations with higher concentration of suspended sediments, peak of around $806 \mathrm{~nm}$ was observed. Table 2 shows statistics of the water quality parameter collected over the study areas along with field dates.

A statistical comparison between modelled and AVIRIS-derived $R_{\mathrm{rs}}$ values was carried out to select the site-specific parameter (bottom type, sediment type and CDOM slope) with utmost care. Based on the published literature over the study site ${ }^{20,21}$, three types of bottom albedo spectral shapes (normalized at $550 \mathrm{~nm}$ ) were taken as an input in the forward simulations of $r_{\mathrm{rs}}$, i.e. sand, small vegetation and heavy vegetation ${ }^{3}$. The bottom type was varied from sand to small vegetation and heavy vegetation while keeping CDOM slope, $Y$ values and all other constituents constant. $R^{2}$ and RMSE were selected as the factors to decide the best suitable bottom type based on spectral matching. Sandy bottom type gave the best correlation with minimum RMSE and was selected for further simulations. Similarly, for CDOM slope and $Y$ parameter, the values were varied for $0.011-0.022 \mathrm{~m}^{-1}$ and $0-2$ respectively. Finally, we have reached the decision that over this study region, the best suitable configuration for running the forward simulations includes sand bottom type, CDOM slope of $0.020 \mathrm{~m}^{-1}$ along with $Y$ factor value of 1 . Table 3 shows detailed statistics of these three independent variables.

Figure 5 shows SAM-classified turbidity image over River Ganga at Buxar and Howrah. In Buxar, the spectra were divided into three classes of $<8,8-12$ and $>12$ NTU based on the frequency distribution.

Similarly, in Howrah, the spectra were merged into five classes, namely $<20,20-40,40-60,60-80$ and $>80$ NTU. Over Buxar region, it was seen from the results that turbidity of the main stream had increased at station 7 as a result of a tributary joining at this location. Close to the river bank, the water was more turbid in 

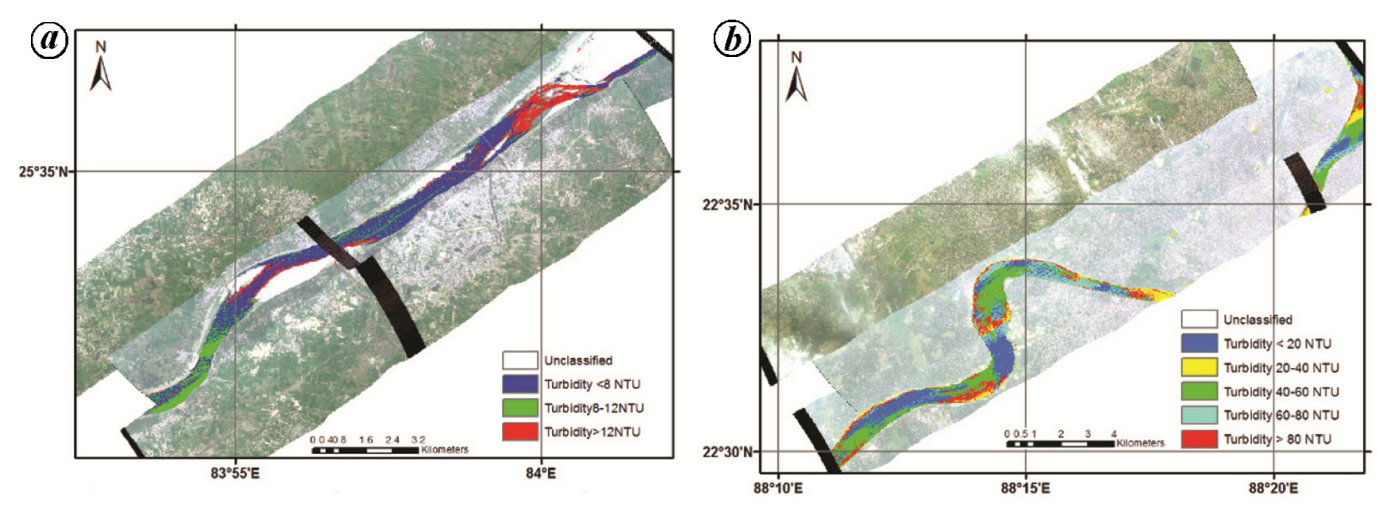

Figure 5. Spectral angle mapper classified turbidity image over Ganga River at Buxar (a) and Howrah (b).
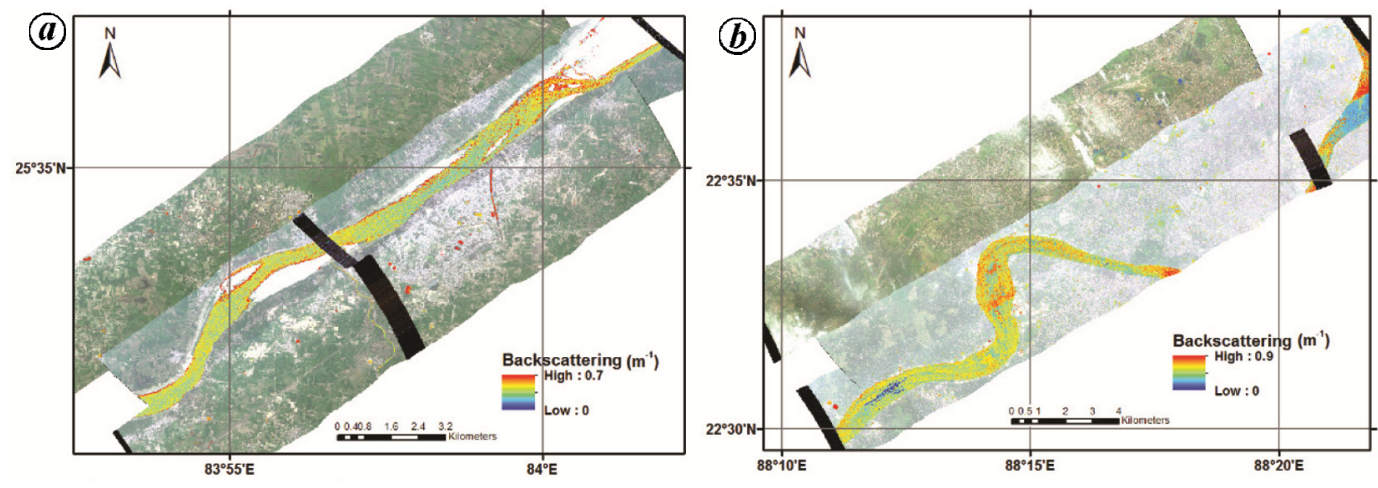

Figure 6. Variability of particle backscattering due to suspended particles over Ganga River at Buxar (a) and Howrah (b).

comparison to the centre. While at Howrah site, it was observed that the spectral profiles obtained from the AVIRIS-NG data over sample locations did not match the turbidity values of the samples. This could be due to the fact that the date of flight was different from the date of sample collection.

Figure 6 shows the analytically derived $b_{\mathrm{bp}}(400)$ that can be considered as the representative of turbidity. Particle backscattering coefficient was found to be factor of 0.018 times the turbidity (NTU). According to a laboratory study for turbid waters performed by Lobo et al. ${ }^{22}$, similar relationship (factor ranging from 0.021 to 0.030 ) between backscattering due to particulate matter and turbidity values was found for three different wavelengths (470, 532 and $660 \mathrm{~nm}$ ) (there Figure 2). The values of River Ganga $b_{\mathrm{bp}}(400)$ at Buxar was found to vary within range $0.2-0.76 \mathrm{~m}^{-1}$, with mean value of $0.34 \mathrm{~m}^{-1}$. While analysing individual spectra at the in situ station location, it was observed that there was an increase in turbidity $\left(0.72 \mathrm{~m}^{-1}\right)$ at station 7 compared to its preceding points. A stream joins the main river before the observation point. It can be clearly inferred that the sewage entering into the main stream had drastically increased the water turbidity. Apart from observation point 7, a higher turbidity value was observed at station 17 . The banks of the river adjacent to this location had profuse growth of waterweeds that would have led to an increased presence of chlorophyll.

At Howrah site $b_{\mathrm{bp}}(400)$ values varied from 0.2 to $1 \mathrm{~m}^{-1}$, with mean value of $0.55 \mathrm{~m}^{-1}$, which is considerably higher than that is observed in Buxar. That may be due to the influence of tidal effects. The passage of ships and ferryboats also keeps the sediments in suspension, which will further increase the turbidity in this stretch. Highest backscattering was observed at stations 12 and 24, i.e. 0.83 and $0.72 \mathrm{~m}^{-1}$ respectively. These two stations are adjacent to Nala and Botanical Garden respectively, where there is probable discharge of effluents into the river.

Over Chilika lagoon, based on the field-measured turbidity values, the field spectral library was classified into seven classes <5, 5-10, 10-15, 15-25, 25-45, 45100 and $>100$ NTU. Figure 7 shows the SAM-derived turbidity map over Chilika lagoon. At each location, the spectral similarity score was more than 0.8 , which indicates better matching of two spectra (field and image).

Figure 8 shows the results obtained over Chilika lagoon for turbidity using AVIRIS scenes, where particle backscattering was found to be varying within the range $0.16-1 \mathrm{~m}^{-1}$, with mean value of $0.39 \mathrm{~m}^{-1}$, and standard deviation of $0.26 \mathrm{~m}^{-1}$. This indicates that in the Chilika there is greater variability, starting from clear productive waters to highly turbid waters. Also water was more 
turbid in the northern sector that may be due to the river input and resuspension from shallow bathymetry. At the northern end, tributaries of the Mahanadi River, such as Daya, Nuna and Bhargavi join the lagoon and are responsible for the large freshwater and sediment flux to the Chilika.

The analytical derived absorption due to phytoplankton at $440 \mathrm{~nm}\left(a_{\phi}(440)\right)$ can be converted into chlorophyll concentration if 'specific absorption coefficient' for that region is known. However, as laboratory-measured value was not available for the same, the following equation was used $^{23}$

$$
\text { Chl } a=\frac{a_{\phi}(440)\left[0.86+0.16 \ln \left(a_{\phi}(440)\right)\right]}{a_{\phi}^{*}(675)}
$$

In addition to the phytoplankton absorption, chlorophyll concentration also depends on $a_{\phi}^{*}(675)$. This value varies regionally and seasonally, but it has been shown to be more stable than $a_{\phi}^{*}(440)$ due to less influence of 'package effect' at $675 \mathrm{~nm}$ (ref. 23). A study that includes

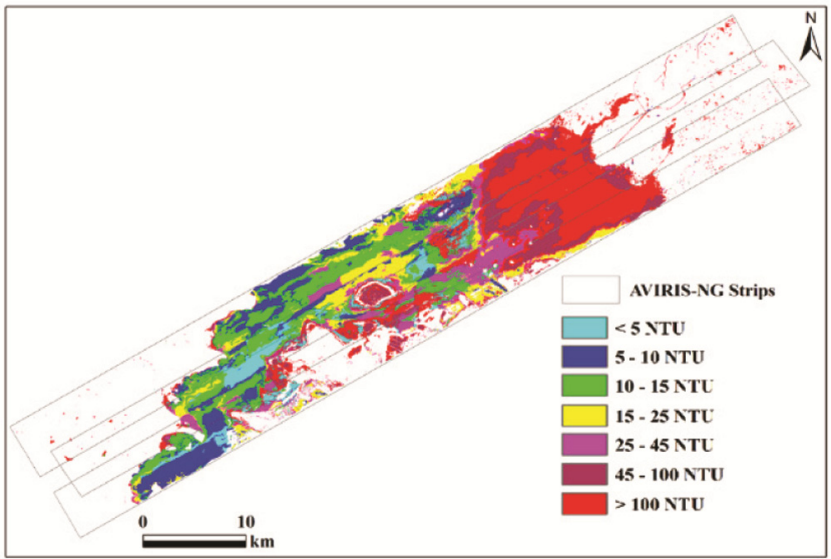

Figure 7. SAM classified turbidity image over Chilika lagoon.

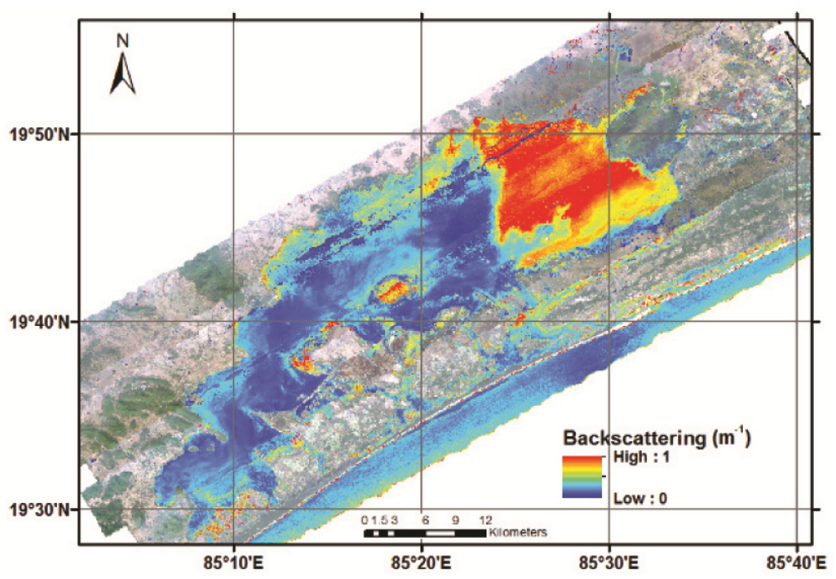

Figure 8. Variability of particle backscattering due to suspended particles variability over Chilika lagoon. optically complex waters ${ }^{24}$ shows that $a_{\phi}^{*}(440)$ of $0.17 \mathrm{~m}^{-1}$ approximately equals a Chl- $a$ concentration of $5 \mathrm{mg} / \mathrm{m}^{3}$. Figure 9 shows the variability of $a_{\phi}(440)$ over River Ganga at Buxar and Howrah. The $a_{\phi}(440)$ was found to vary between 0.04 and $0.6 \mathrm{~m}^{-1}$, with mean value of $0.28 \mathrm{~m}^{-1}$ in the Ganga near Buxar. The mean chlorophyll
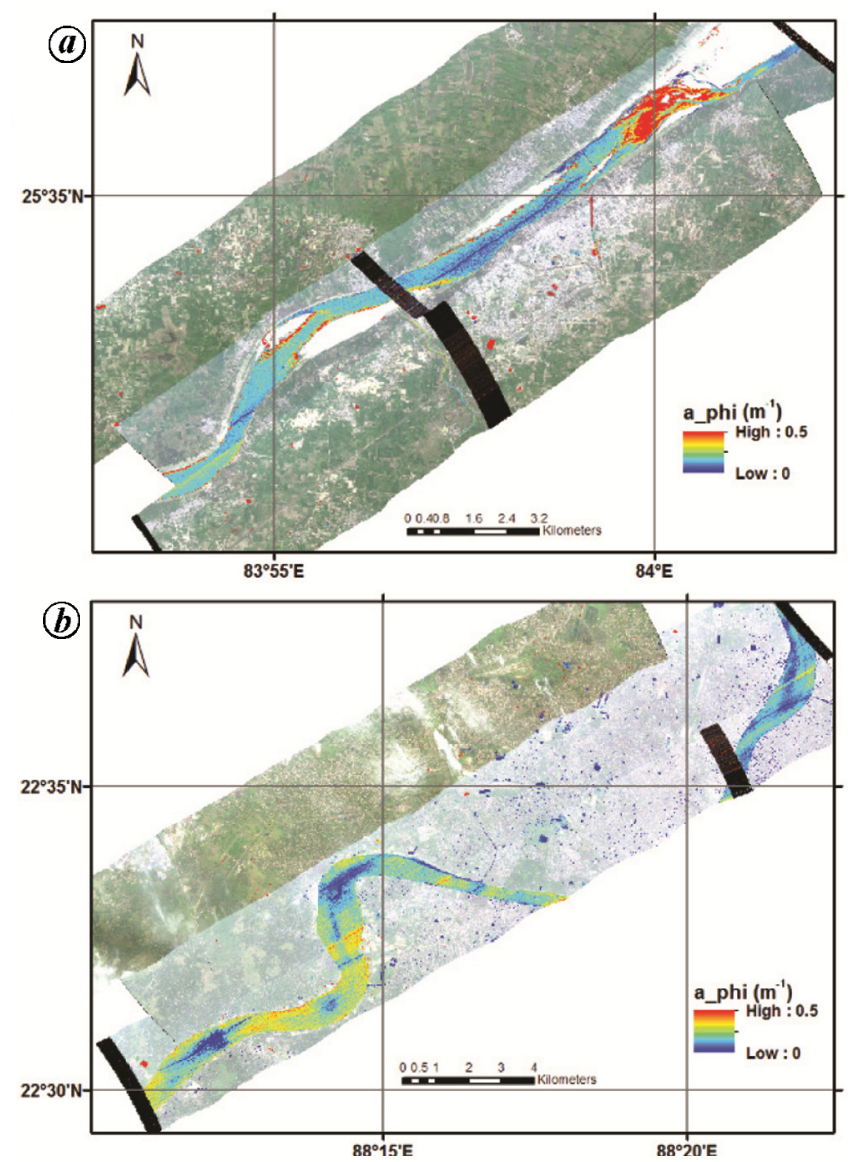

Figure 9. Variability of particle absorption due to phytoplankton $\left(a_{\varphi}(440)\right)$ over Ganga River at Buxar (a) and Howrah (b).

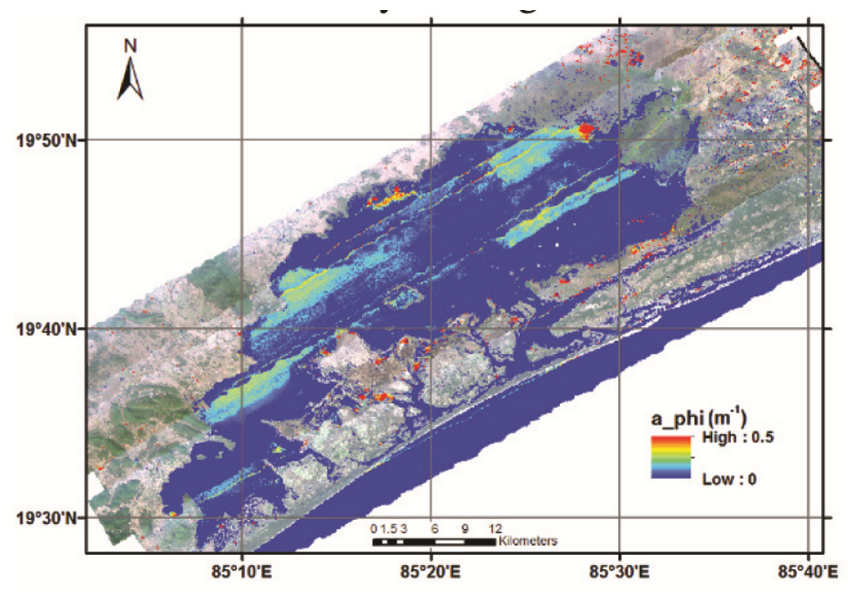

Figure 10. Variability of absorption due to phytoplankton $\left(a_{\phi}\right)$ over Chilika lagoon. 


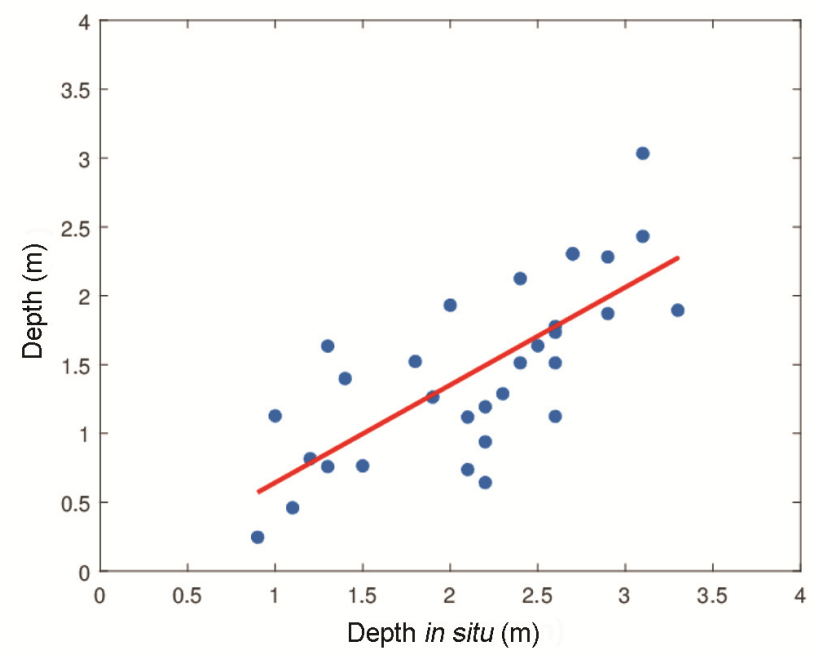

Figure 11. Comparison between bottom depths derived using AVIRIS versus in situ echo sounder-measured depth.

concentration here was close to $20 \mathrm{mg} / \mathrm{m}^{3}$. These results clearly represent the case of typically productive waters. However, at Howrah the mean absorption due to phytoplankton was less than $0.1 \mathrm{~m}^{-1}$, which is very less compared to Buxar.

Absorption due to phytoplankton in the Chilika lagoon varied between 0.08 and $0.5 \mathrm{~m}^{-1}$ (Figure 10) that lead to variation in chlorophyll between 1.84 and $19 \mathrm{mg} / \mathrm{m}^{3}$. Spatially, the northern part of the lagoon showed higher values for chlorophyll, with absorption due to phytoplankton close to $0.5 \mathrm{~m}^{-1}$. This may be due to nutrient-rich freshwater input from rivers. The minimum chlorophyll found in the southern sector could be attributed to less availability of inorganic nutrients.

Another possible reason for high turbidity in the northern sector could be due to resuspension from shallow bathymetry. The depth retrieved using semi-analytical inversion was found to be in the range $0.1-3.1 \mathrm{~m}$, i.e. $0.1 \mathrm{~m}$ in the northern sector and $3.1 \mathrm{~m}$ in the southern sector. Figure 11 shows a comparison between $r_{\mathrm{rs}}$ inverted depths with the in situ echo sounder measured depths over the in situ locations of Chilika lagoon. Both depths were found to be in good agreement with coefficient of correlation 0.8 and RMSE of $60 \mathrm{~cm}$.

\section{Conclusion}

The water quality of River Ganga and Chilika lake with regard to turbidity has been analysed using two different approaches, i.e. spectral similarity and semi-analytical inversion. A spectral library was developed using sophisticated instruments like field spectro-radiometer, turbidity meter and hand-held GPS. Between the two sites over River Ganga, Howrah had more turbidity when compared to Buxar. The possible reason could be due to tidal influence of the Bay of Bengal in Howrah site. It was observed in the Buxar site that small input of domestic sewage had increased the turbidity of that sector. After some distance the turbidity was less, indicating uniform mixing of polluted water with the main stream. The results support that the high spatial resolution hyperspectral imagery can identify hot spots of point source pollution like sewage discharges through drainage into a river. This will provide useful information to pollution control agencies to identify potential locations of water contamination. However, in the case of River Ganga near Howrah, since the time of flight and field data collected were not concurrent, there was no significant relationship between the spectra from AVIRIS data and the fieldmeasured water quality parameters. Over Chilika lagoon, water was more turbid in the northern sector due to the river input and resuspension from shallow bathymetry. At the northern end, tributaries of the Mahanadi River, join the lagoon and are responsible for the large freshwater and sediment flux in to it. The sediments brought by flowing water increase the concentration of suspended materials and hence turbidity, which in turn alters light attenuation by water. The spectral library developed in this study will further be improved by collecting more field spectra during different seasons and conditions. The findings of the study also depict effectiveness of the semi-analytical and spectral similarity analysis in quantification of water quality parameters.

1. Ritchie, J. C., Zimba, P. V. and Everitt, J. H., Remote sensing techniques to assess water quality. Photogram. Eng. Remote Sensing, 2003, 69, 695-704.

2. Agrawal, A., Pandey, R. S. and Sharma, B., Water pollution with special reference to pesticide contamination in India. J. Water Resour. Prot., 2010, 2, 432-448.

3. Lee, Z., Carder, K. L., Mobley, C. D., Steward, R. G. and Patch, J. S., Hyperspectral remote sensing for shallow waters: 2. Deriving bottom depths and water properties by optimization. Appl. Opt., 1999, 38, 3831-3843.

4. Trivedi R. C., Water quality of the Ganga River - an overview. Aquat. Ecosyst. Health Manage., 2010, 13(4), 347-351.

5. Garg, V. et al., Spectral similarity approach for mapping turbidity of an Inland waterbody. J. Hydrol., 2017, 550, 527-537.

6. Brando, V. E. and Dekker, A. G., Satellite hyperspectral remote sensing for estimating estuarine and coastal water quality. IEEE Trans. Geosci. Remote Sensing, 2003, 41(6), 1378-1387.

7. Van der Meer, F., The effectiveness of spectral similarity measures for the analysis of hyperspectral imagery. Int. J. Appl. Earth Observ. Geoinform., 2006, 8, 3-17.

8. Van der Meer, F. and Bakker, W., Cross correlogram spectral matching (CCSM): application to surface mineralogical mapping using AVIRIS data from Cuprite, Nevada. Remote Sensing Environ., 1997, 61(3), 371-382.

9. Kruse, F. A., Lefkoff, A. B., Boardman, J. W., Heidebrecht, K. B., Shapiro, A. T., Barloon, P. J. and Goetz, A. F. H., The spectral image processing system (SIPS) - interactive visualization and analysis of imaging spectrometer data. Remote Sensing Environ., 1993, 44, 145-163.

10. Chang, C. I., An information theoretic-based approach to spectral variability, similarity and discriminability for hyperspectral image analysis. IEEE Trans. Inf. Theory, 2000, 46(5), 1927-1932. 
11. Green, A. A. and Craig, M. D., Analysis of aircraft spectrometer data with logarithmic residuals. In Proceedings of AIS Workshop, JPL Publication 85-41, 8-10 April 1985, Jet Propulsion Laboratory, Pasadena, California, 1985, pp. 111-119.

12. Clark, R. N., King, T. V. V. and Gorelick, N. S., Automatic continuum analysis of reflectance spectra. In Proceedings of Third AIS Workshop (2-4 June 1987), JPL Publication 87-30, Jet Propulsion Laboratory, Pasadena, California, 1987, pp. 138-142.

13. Kokaly, R. F., Investigating a physical basis for spectroscopic estimates of leaf nitrogen concentration. Remote Sensing Environ., 2001, 75, 153-161.

14. Lee, Z., Carder, K. L., Mobley, C. D., Steward, R. G. Patch, J. S., Hyperspectral remote sensing for shallow waters: I. A semianalytical model. Appl. Opt., 1998, 37, 6329-6338.

15. Lee, Z., Carder, K. L., Chen R. F. and Peacock, T. G., Properties of the water column and bottom derived from Airborne Visible Infrared Imaging Spectrometer (AVIRIS) data. J. Geophys. Res., 2001, 106, 11639-11651.

16. Gege, P., The water colour simulator WASI: an integrating software tool for analysis and simulation of in situ spectra. Comput. Geosci., 2004, 30, 523-532.

17. Pope, R. M. and Fry, E. S., Absorption spectrum (380-700 nm) of pure water. II. Integrating cavity measurements. Appl. Opt., 1997, 36(33), 8710-8723.

18. Bricaud, A., Morel, A. and Prieur, L., Absorption by dissolved organic matter of the sea (yellow substance) in the UV and visible domains. Limnol. Oceanogr., 1981, 26(1), 43-53.

19. Morel, A. and Prieur, L., Analysis of variations in ocean colour. Limnol. Oceanogr., 1977, 22, 709-722.

20. Mahapatro, D., Panigrahy, R. C., Panda, S. and Mishra, R. K., Checklist of intertidal benthic macrofauna of a brackish water coastal lagoon on east coast of India: the Chilika lake. Int. J. Mar. Sci., 2015, 5(33), 1-13.

21. Sahoo, R. K., Mohanty, P. K., Pradhan, S., Pradhan, U. K. and Samal, R. N., Bed sediment characteristics and transport processes along the inlet channel of Chilika Lagoon (India). Indian J. Geo.Mar. Sci., 2018, 47(2), 301-307.

22. Lobo, F. L., Costa, M., Phillips, S., Young, E. and McGregor, C., Light backscattering in turbid freshwater: a laboratory investigation. J. Appl. Remote Sensing, 2014, 8, doi:10.1117/1.jrs. 8.083611 .

23. Lee, Z., Visible-infrared remote-sensing model and applications for ocean waters, Ph D thesis, University of South Florida, 1994.

24. Prieur, L. and Sathyendranath, S., An optical classification of coastal and oceanic waters based on the specific spectral absorption curves of phytoplankton pigments, dissolved organic matter, and other particulate materials. Limonol. Oceanogr., 1981, 2, 671689.

ACKNOWLEDGEMENTS. We thank the senior officials of Space Applications Centre (SAC), National Remote Sensing Centre (NRSC) and Indian Institute of Remote Sensing (IIRS) for technical support and guidance during the course of this study. We also thank Dr Raj Kumar, Deputy Director EPSA/SAC, Dr R. P. Singh, Head, LHD/SAC and Dr Bimal Bhattacharya, Science Team Leader (AVIRIS-NG Airborne campaign) for guidance and encouragement; the authorities of ISRO for providing financial grant for this research work (Project Line Item Code: 0303617RM705), and research staff of CDA Bhubaneswar, NIT Patna and Jadavpur University, Kolkata for help.

doi: $10.18520 / \mathrm{cs} / \mathrm{v} 116 / \mathrm{i} 7 / 1172-1181$ 